\title{
Monitoring Geomorphic Change and Catchment Sediment Production to Understand the Erosive Dynamics in a Gullied Channel by Means of High-Resolution DEMs ${ }^{\dagger}$
}

\author{
Alberto Alfonso-Torreño *, Álvaro Gómez-Gutiérrez, Susanne Schnabel, \\ J. Francisco Lavado Contador, Manuel Pulido Fernández and Jesús Barrena-González \\ Research Institute for Sustainable Land Development (INTERRA), University of Extremadura, \\ 10071 Cáceres, Spain; alvgo@unex.es (Á.G.-G.); schnabel@unex.es (S.S.); frlavado@unex.es (J.F.L.C.); \\ mapulidof@unex.es (M.P.F.); barrenaje@unex.es (J.B.-G.) \\ * Correspondence: albertoalfonso@unex.es \\ † Presented at TERRAenVISION 2019, Barcelona, Spain, 2-7 September 2019.
}

Published: 18 May 2020

\begin{abstract}
Gully erosion in valley bottoms is a frequent process with negative consequences in the dehesa environment. Soil loss, decrease of soil and descend in biomass are among the negative aftereffect of gully erosion processes. Studies conducted in agrosilvopastoral systems described the dynamics of gullied channels by means of fixed topographic cross sections or with low spatial resolution Digital Elevation Models (DEMs). Currently, high spatial and temporal resolution DEMs can be produced with spatially distributed information due to the development of new systems, platforms and sensors. Additionally, the rainfall and sediment discharge could also be monitored. This control allows us to relate gully erosion with catchment hydrology. The goals are (1) to quantify the sediment budgets by the spatio-temporal distribution of erosion and/or deposition in the gullied channel, (2) to interpret the geomorphic processes driving erosion and deposition and (3) to analyze the relationship between the morphological change and the catchment runoff and the sediment load. The studied area is a gullied channel located in the SW Iberian Peninsula and developed over a recent sedimentary deposit. The channel reaches an extension of $1 \mathrm{~km}$ in length and $2 \mathrm{~m}$ in depth. The methodology included the following steps: (1) flying the same study area with different time periods using a fixed-wing small Unmanned Aerial System (sUAS) to capture high-resolution aerial images and surveying Ground Control Points (GCPs) using a GNSS, (2) Structure-from-Motion photogrammetry processing using the acquired images and the GCPs to produce high-resolution DEMs for each date, (3) Applying the DEMs of difference approach to estimate topographic changes and to quantify the sediment budget and finally (4) analyzing the relationship between rainfall events, discharge, sediment load and changes in the channel previously estimated. Resulting DEMs and orthophotographs showed a Ground Sampling Distance of $0.02 \mathrm{~m}$ with a georeferencing Root Mean Square Error of $0.03 \mathrm{~m}$. A spatially variable threshold (to differentiate actual geomorphic change from noise or errors) was produced using a Fuzzy Inference System and considering photogrammetric errors, slope and vegetation as factors. The applied method proved to be suitable to interpret the geomorphic changes for the gullied channel. For the 2016-2018 period, the gully showed a positive balance indicating accumulation of sediments coming from the hillslopes of the catchment. It is the period with the highest rainfall when numerous events generated runoff. On the contrary, for the period 2018-2019 a total soil loss of $-119 \mathrm{~m}^{3}$ was estimated.
\end{abstract}

Keywords: DEMs of difference; geomorphic change detection; sUAS; SfM photogrammetry 
(C) 2020 by the authors. Licensee MDPI, Basel, Switzerland. This article is an open access article distributed under the terms and conditions of the Creative Commons Attribution (CC BY) license (http://creativecommons.org/licenses/by/4.0/). 